child of Mr. Lawrence Petre, eleven months old, whom I had previously attended for severe convulsions due to teething. I arrived as soon as possible, and found the child in articulo mortis. He had been in severe convulsions for about an thour or more. He was deeply cyanosed, the limbs were perfectly flaccid, there was no pulse, respiration or heart beat, the pupils were insensitive, and the corneal reflex was absent. The only sign of life was the active cause of his condition-viz., remaining spasm of the diarhragm. Artificial respiration, with special expiratory effort, improved this condition slightly, but spasm recurring, I lanced the gums, which were blue and swollen, and repeated a treatment which I previously successfully carried out on a similar - occasion with the same child-that is, I injected hypodermicaliy $\frac{1}{25}$ gr. of morphia. The child shortly afterwards recovered somewhat, and spasm disappeared. As a prewautionary measure, hearing the bowels had not acted properly for some time previously, I gave half a drop of croton oil on the tongue and put the child to bed in warm blankets, ixc. There was never any reaction. Shortly afterwards I was recalled to the room, and found the child again convulsed, spasm returned, and cedema of the larynx set in. I had frequent occasion to restore the child by artificial respiration, and, seeing by the pupils that the effect of the morphia had been $\checkmark$ ery evanescent, I tried to get expiratory effort by inducing "vomiting with $\frac{1}{36} \mathrm{gr}$. of apomorphia. To aid the circulation $\$$ gave injections of ether and brandy. There was no reaction, and, the trachea becoming obstructed after trying the effect of withdrawing the tongue by means of a thread passed through it, I finally said that tracheotomy was the only chance, and successfully performed it. I cleared the trachea and both bronchi of mucus by suction with a silver catheter and then inserted the tubes. The child now partially recovered, breathing became easy, cyanosis disappeared, and the surface of the body got warm. Subsequently, notwithstanding every effort to support and restore life, and after spending hours nursing the child myself, to the great detriment of some of my other patients, the child died asphyxiated at about 5 A.M. on Jan. 2nd. The results of my labours were an exhumation and post-mortem examination and subsequent inquest at which I was, as you know, entirely exonerated from all blame in the case. I should desire the medical profession generally to consider the importance of the possible frequent occurrence of such a state of things. A man has apparently only to express dissatisfaction to have an inquest hurled at the head of his medical attendant because a child cannot be saved. Extreme cases must be left unaided if such a state of things is to continue possible; and, as in my case, the medical attendant is exposed to great risk, annoyance, and expense, with barely sufficient time allowed him to procure adequate counsel. In this case the proceedings were kept from me till twenty hours before the preliminary inquiry, and I had to hunt London at past midmight for forensic advice.-I am, Sirs, yours truly,

Jan. 29th, 1894.

E. Clokte Smith,

\section{PROPOSAL FOR AMENDING THE SYSTEM OF MEDICAL CLUBS AND ASSOCIATIONS. \\ To the Editors of THE LANCET.}

SIRs, - Whilst the subject of clubs, medical aid associations, and dispensaries is attracting so much attention, may I lay before the profession for criticism a suggestion which I believe to be original? The main faults of the present system appear to be an inadequate remuneration, the contract system, and an induced tendency on the part of the practitioner to hurry over his work. My suggestion is that, instead of paying the practitioner for what must necessarily be an ancertain amount of work, the members should combine, as now, and appoint a committee and treasurer, who shall receive vheir subscriptions. So far this does not differ from the present custom. Now, instead of contracting with one medical man, as heretofore, to do all the work they should allow their members to call in any practitioner whom they choose, who shall agree to see them for his usual visiting or surgery fee. The practitioner will then send in his bill, stating the number of visits or attendances of "John Smith," to the committee, who shall agree to pay him quarterly for actual work done. To aroid the inconveniences of dispensing, arrangements could be made to pay the druggist in the same way. I would suggest that in no case whatsoever should the consulting fee include medicine. Patients of all descriptions would then be brought to realise that it is for the advice they piy the medical man, and not for the d'ugs.
For the above scheme I would claim the following advan. tages : that if the practitioner is adequately remunerated under the present system he would not suffer under the new; should a time of epidemics arise, as at present, his pay would increase in proportion, and as each individual stands to him in the relation of a private patient his interest would be more keen and his attention less divided, more especially as the patient could at any time during his illness change his medical adviser. On the other hand, when there was but little illness the committee could lay by a small reserve fund for a busy time without being reproached on the ground that they are making money out of their medical man. Again, the patient not being able to say at present, "Well, I have paid the medical man why should I not have him?" he would be less likely to consult the practitioner for the most trivial complaints, and such an instance as a man sending for the medical attendant at midnight because his tooth ached would be of less frequent occurrence, as the committee would soon interfere. Again, minor surgical cases requiring, as they do, expensive dressings could be met by a slightly increased fee on due representation to the committee.

I am, Sirs, yours faithfully,

Weston-super-Mare, Jan. 30th, 1891. MURTAUGH HOUGHTON.

** Our correspondent's letter is interesting. The fear is that the members of clubs and associations will not see things in the same light. Undoubtedly the great desideratum is to approximate club practice to private practice in the two respects of better pay for the practitioner and the right of choice for the patient. But the club concedes its right of individual choice for the very purpose of obtaining attendance on lower terms by having a medical man of its own, more or less under its own control, with, however, very questionable results for the dignity of the profession or the advantage of the patients.-ED. L.

\section{"OBSTETRIC AND GYN ACOLOGICAL NURSING."}

\section{To the Editors of THE LANCET.}

SIRs,-I do not see anything in Dr. More Madden's letter in THE LANCET of the 27th inst. that is at variance with the passages he quotes from the notice in your issue of Jan. 20th. The review did not say that there is no in. formation as regards the employment of antiseptics in midwifery, but that in teaching persons who have usually had a very limited general education more prominence should be given to the subject, and more especially that plain directions concerning antiseptics should have appeared in the chapter on the management of natural labour, in which there is no mention whatever of antiseptics. Again, in teaching the class of persons for whom the book is more especially intended I think directions should be particular rather than general ; for instance, instead of telling the nurse to have the antiseptic solution ready (as on p. 67), mention should be made of some particular solution, such as 1 in 1000 corrosive sublimate lotion, or whatever antiseptic solution the author considers best. The other passage of the notice to which Dr. More Madden refers- "It is of little avail for the medical man to employ elaborate antiseptic measures when a nurse, whose hands are anything but aseptic, bas already examined the patient "- -had reference to the account of the special duties of the monthly nurse. From this account it clearly appears that part of the nurse's duty is to examine the patient before sending for the medical attendant. It seems to me to be quite wrong for a nurse to do so, unless specially directed by the medical man. The passage Dr. More Madden quotes from his book, p. 141-“"The nurse's primary duty in every puerperal case is the removal of all septic matter or possible sources of infection, not only from the external parts and vaginal orifice by frequent spong. ing or washing out with some antiseptic solution, but also by the thorough cleansing out of the uterus and vagina when necessary by hot water or antiseptic douching with the irrigator, subject to the approval of the doctor, if there be one in attendance" - evidently points to circumstances possibly arising in which a nurse would be right to undertake washing out the uterus, even without the direction of a medical man. I should say washing out the uterus should never be left to a nurse. I do not think either that "washing by use of nailbrush, hot water, and carbolic soap, "though good so far as it goes, produces the nearest approach to 